\title{
Automated Analysis of Non-steroidal Anti-inflammatory Drugs in Environmental Water by On-line In-tube Solid-phase Microextraction Coupled with Liquid Chromatography-Tandem Mass Spectrometry
}

\author{
Kurie OHCHO, Keita SAITO and Hiroyuki KATAOKA \\ School of Pharmacy, Shujitsu University \\ (1-6-1 Nishigawara, Okayama, Okayama 703-8516 Japan)
}

[Received May 7, 2008; Accepted August 22, 2008]

\begin{abstract}
Summary
A simple and sensitive method for the simultaneous determination of 15 non-steroidal antiinflammatory drugs (NSAIDs)—acetaminophen, ibuprofen, naproxen, fenoprofen, flurbiprofen, loxoprofen, ketoprofen, mefenamic acid, flufenamic acid, diclofenac, tolfenamic acid, oxaprozin, phenylbutazone, indomethacin, and acemetacin-in environmental water was developed. This method consists of in-tube solid-phase microextraction (SPME) coupled with liquid chromatography-tandem mass spectrometry (LC-MS-MS). These NSAIDs were analyzed within 10 min using an ODS-3 column and $5 \mathrm{mM}$ aqueous ammonium formate/acetonitrile (60/40, $\mathrm{v} / \mathrm{v})$ as the mobile phase. Electrospray ionization conditions in the negative ion mode were optimized for MS-MS detection of these drugs. The optimum in-tube SPME conditions were 20 draw/eject cycles of $40 \mu \ell$ of sample at a flow rate of $150 \mu \ell / \min$ using a Carboxen-1006 PLOT capillary column as an extraction device. The extracted NSAIDs were easily desorbed from the capillary by passage of mobile phase. Using the in-tube SPME/LC-MS-MS method, good linearity of the calibration curve $(r \geq 0.9997)$ was obtained in the concentration range from $0.1 \sim 10 \mathrm{ng} / \mathrm{m} \ell$ for all compounds examined. The limits of detection $(\mathrm{S} / \mathrm{N}=3)$ of NSAIDs ranged from $5 \sim 65 \mathrm{pg} / \mathrm{m} \ell$. This method could be successfully applied to analysis of surface water and wastewater without any other pretreatment or interference peaks. The recoveries of NSAIDs spiked into river water were above $80 \%$, and the relative standard deviations were below $8.3 \%$. Among the NSAIDs tested in this study, loxoprofen was detected in hospital wastewater at $458 \mathrm{pg} / \mathrm{m} \ell$.
\end{abstract}

Key words: in-tube solid-phase microextraction, automated sample preparation, liquid chromatography-tandem mass spectrometry, non-steroidal anti-inflammatory drugs, environmental water samples

\section{INTRODUCTION}

In recent years, there has been an increase in concern regarding the occurrence, fate, and toxicity of pharmaceuticals and personal care products in the aquatic environment ${ }^{1-5)}$. A wide range of these compounds, some of which have the potential to harm aquatic life even in small quantities, has been detected at ppb or ppt levels in environmental waters throughout the world. Many of these environmental pollutants 
are produced not only by veterinary and human excretion but also by the disposal of medicines in hospital and household waste.

Non-steroidal anti-inflammatory drugs (NSAIDs) are widely used in human and animal health care, mainly as antipyretic and painkilling drugs. There are more than 50 different types of NSAID on the market in Japan, some of which have consumption rates of over $10 \mathrm{t}$ per year. NSAIDs have been detected in environmental samples, including wastewater and surface water $^{6-20)}$, and a number of studies have shown that NSAIDs are not eliminated in sewage treatment plants because of their polar structures and high stability. In addition, there is a great deal of concern regarding the behavior and fate of NSAIDs in environment waters due to their pharmacological activity. Therefore, it is necessary to develop a simple, rapid, and sensitive analytical method for monitoring of NSAIDs at naturally occurring levels.

Analysis of NSAIDs in environmental samples has been carried out by gas chromatography-mass spectrometry (GC-MS) ${ }^{13,14}$, high performance liquid chromatography (HPLC) with $\mathrm{UV}^{15,16)}$, LC-mass spectrometry $(\mathrm{LC}-\mathrm{MS})^{16)}$, and LC-tandem mass spectrometry (LCMS-MS) ${ }^{17-20)}$. However, GC-MS methods require timeconsuming derivatization of these compounds. Although LC-MS-MS methods are highly sensitive and selective, the sensitivities of HPLC-UV and LC-MS methods are insufficient for application to analysis of environmental water samples. Furthermore, most of these methods require relatively large sample volumes and laborious pretreatment of samples prior to analysis. The details of these analytical methods for determining NSAIDs in environmental samples have been summarized in recent reviews ${ }^{21-23)}$.

The in-tube solid-phase microextracation (SPME) technique ${ }^{24}$, using an open tubular fused-silica capillary with an inner surface coating as the SPME device, is simple and can be easily coupled on-line with HPLC and LC-MS. In-tube SPME allows convenient automation of the extraction process, which not only reduces the analysis time, but also provides better accuracy, precision, and sensitivity than off-line manual techniques. We have reported the development of the intube SPME method for determination of various compounds, such as drugs and endocrine disruptors, by coupling with $\mathrm{HPLC}^{25)}$, LC-MS ${ }^{26,27)}$, and $\mathrm{LC}-\mathrm{MS}^{2} \mathrm{MS}^{28,29}$. The details of the in-tube SPME technique and its ap- plications have also been reviewed ${ }^{30)}$.

In the present study, we developed an automated on-line in-tube SPME/LC-MS-MS method for the simultaneous determination of 15 NSAIDs in environmental waters to achieve high throughput analysis. We also used this method for determination of NSAIDs in several environmental water samples.

\section{MATERIALS AND METHODS}

\section{Materials}

Fig. 1 shows the structures of the 15 NSAIDs used in this study. Acetaminophen, ibuprofen, naproxen, fenoprofen, flurbiprofen, loxoprofen, ketoprofen, mefenamic acid, flufenamic acid, diclofenac, tolfenamic acid, oxaprozin, phenylbutazone, indometacin, and acemetacin were purchased from Sigma-Aldrich (Saint Quentin Fallaviers, France). Each compound was dissolved in methanol to make a stock solution at a concentration of $1 \mathrm{mg} / \mathrm{m} \ell$. These stock solutions were stored at $4^{\circ} \mathrm{C}$ and diluted to the required concentrations with pure water prior to use. LC-MS grade acetonitrile and water as the mobile phase were purchased from Kanto Kagaku (Tokyo, Japan). All other chemicals were of analytical grade.

\section{Sample collection and preparation}

Surface water and wastewater samples were collected in $1-\ell$ pre-cleaned amber glass bottles with polytetrafluoroethylene (PTFE) lined caps, and filtrated through $0.2-\mu \mathrm{m}$ nylon syringe filters $13 \mathrm{~mm}$ in diameter (Tosoh, Tokyo, Japan) if necessary. Sampling was performed at six sites in the area around Asahi River and Sasagase River in Okayama City, including wastewater from hospitals and wastewater treatment plants (WWTP), and tap water from our laboratory. The samples were stored in the dark at $4^{\circ} \mathrm{C}$ and then analyzed within 48 h. Samples $(0.5 \sim 0.9 \mathrm{~m} \ell)$ were added to $0.1 \mathrm{~m} \ell$ of $200 \mathrm{mM}$ Tris- $\mathrm{HCl}$ buffer (pH 8.0), and made up to a final volume of 1 me with water in 2 -m $\ell$ screw-cap autosampler vials equipped with silicon/PTFE septa, and the vials were then set onto the sample tray in the autosampler.

\section{Instrument and analytical conditions}

The HPLC system was a Model 1100 series (Agilent Technologies, Boeblingen Germany), which consisted of a binary pump, an on-line-degasser, an auto- 


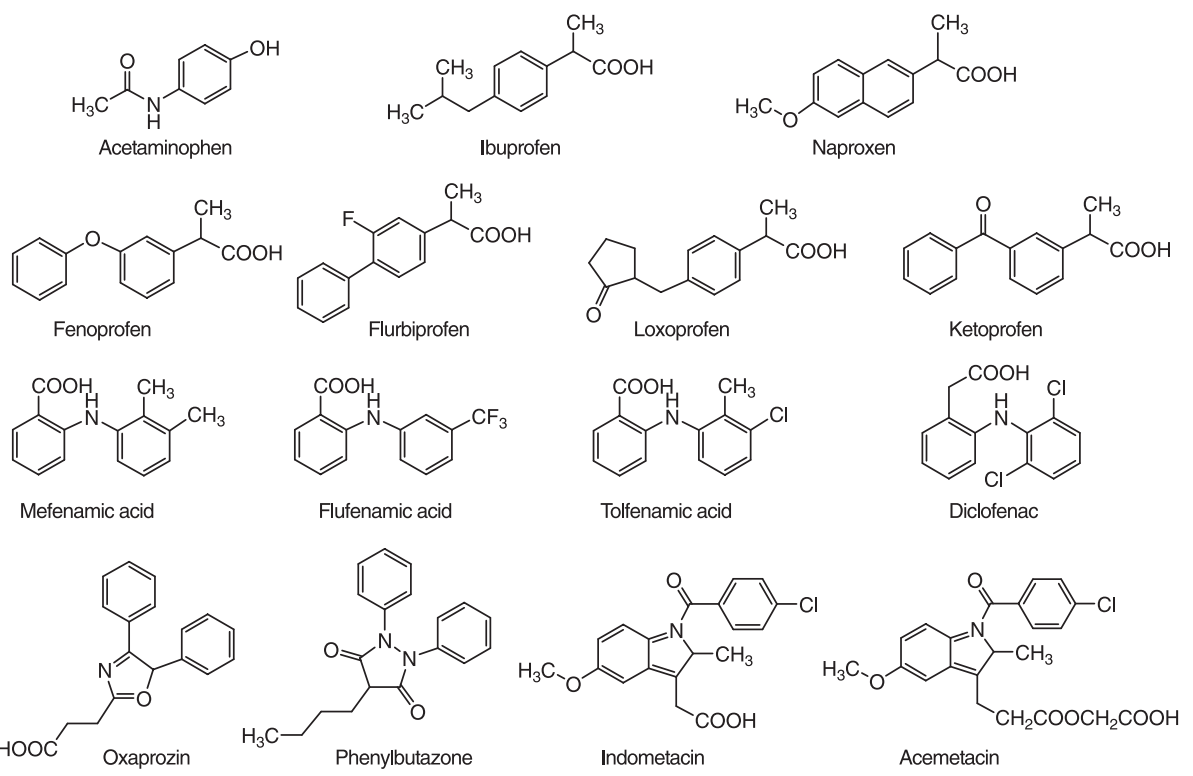

Fig. 1 Structures of the 15 non-steroidal anti-inflammatory drugs examined in this study

sampler, a column compartment, a diode array detector, and an HP ChemStation. An ODS-3 column (100 mm $\times 2.1 \mathrm{~mm}$, particle size $5 \mu \mathrm{m}$; GL Science, Tokyo, Japan) was used for HPLC separation. Chromatography was performed by isocratic reverse phase separation with $5 \mathrm{mM}$ aqueous ammonium formate/acetonitrile $(60 / 40 \mathrm{v} / \mathrm{v})$ at a flow rate of $0.3 \mathrm{~m} / / \mathrm{min}$ and column temperature of $40^{\circ} \mathrm{C}$.

Electrospray MS-MS for the 15 NSAIDs was performed on an API 4000 triple quadruple mass spectrometer (Applied Biosystems, Foster City, CA, USA), equipped with a turbo ion spray interface operated in negative ion mode at $4500 \mathrm{~V}$ and $450^{\circ} \mathrm{C}$. Nitrogen as a nebulizing and drying gas was generated from compressed air using a Kaken $\mathrm{N}_{2}$ generator (System Instruments Co., Ltd., Tokyo, Japan). The ion sources gas 1 (GS1) and 2 (GS2) were set at 40 and $50 \mathrm{l} / \mathrm{min}$, respectively. The curtain gas (CUR) flow was set at 40 $\ell / \mathrm{min}$ and the collision gas (CAD) at $3.0 \mathrm{l} / \mathrm{min}$. Quantification was performed by multiple reaction monitoring (MRM) of the deprotonated precursor molecular ions $[\mathrm{M}-\mathrm{H}]^{-}$and the related product ion for NSAIDs. Quadrupoles Q1 and Q3 were set on unit resolution. MRM in the negative ionization mode was performed using a dwell time of $150 \mathrm{~ms}$ per transition to detect ion pairs. Table 1 shows the optimized MS-MS conditions for each compound. LC-MS-MS data were processed using Analyst Software 1.3.1 (AppliedBiosystems).

\section{In-tube solid-phase microextraction}

As shown in Fig 2, a Carboxen-1006 porous layer open tubular (PLOT) capillary column (60 $\mathrm{cm} \times 0.32$ mm i.d., $17 \mu \mathrm{m}$ film thickness; Supelco, Bellefonte, PA, USA) was used as the in-tube SPME device and was placed between the injection needle and the injection loop retained in the system to avoid fouling of the metering pump. Capillary connections were facilitated by use of a $2.5 \mathrm{~cm}$ sleeve of $1 / 16$-in polyetheretherketone (PEEK) tubing at each end of the capillary. PEEK tubing with an internal diameter of $330 \mu \mathrm{m}$ was shown to be suitable to accommodate the capillary used. Standard 1/16-in stainless steel nuts, ferrules, and connectors were used to complete the connections. The autosampler software was programmed to control the in-tube SPME extraction, desorption, and injection. (A) Sampling and extraction: vials (2 $\mathrm{m} \ell$ ) were filled with $1 \mathrm{~m} \ell$ of sample for extraction, and set into the autosampler programmed to control the SPME extraction and desorption technique. In addition, 2-m $\ell$ autosampler vials with a septum, one containing 1.5 $\mathrm{m} \ell$ of methanol and another containing $1.5 \mathrm{~m} \ell$ of water, were set into the autosampler. The capillary column was washed and conditioned by two repeated draw/eject cycles (40 $\mu \ell$ each) of these solvents, and then a 50- $\mu \ell$ air plug was drawn prior to the extraction step. The extraction of 15 NSAIDs onto the capillary coating was performed by 20 repeated draw/eject 
(A)

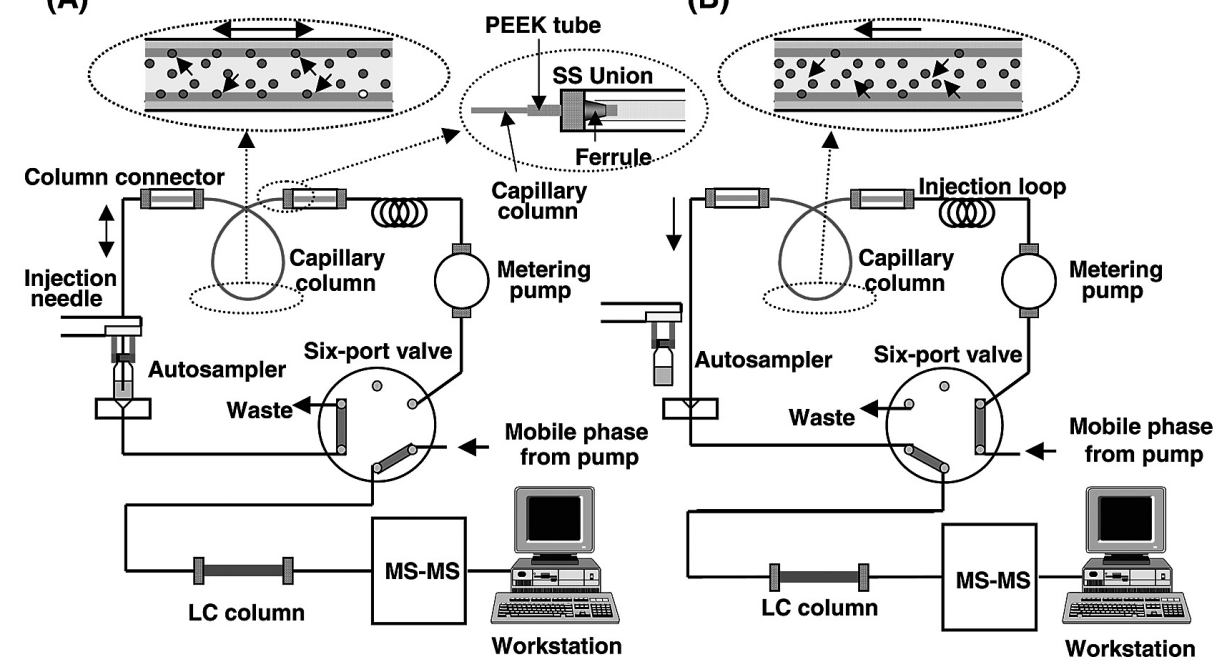

Fig. 2 Schematic diagram of on-line in-tube SPME/LC-MS-MS system. (A) Sampling and extraction; (B) desorption and LC-MS-MS analysis

cycles of $40 \mu \ell$ of sample at a flow rate of $150 \mu \ell / \mathrm{min}$ with the six-port valve in the LOAD position. After extraction, the tip of the injection needle was washed by one draw/eject cycle of $2 \mu \ell$ of methanol. (B) Desorption and LC-MS-MS analysis: the extracted compounds were desorbed from the capillary coating with the mobile phase and transported to the LC column by switching the six-port valve to the INJECT position, and detected with the MS-MS system. During analysis, the Carboxen-1006 PLOT capillary was washed and conditioned with mobile phase for the next extraction.

\section{RESULTS AND DISCUSSION}

\section{LC-MS-MS analysis of NSAIDs}

For MS-MS operation, ESI negative ion mode was most effective for ionization of the 15 NSAIDs examined in this study. A solution of $100 \mathrm{ng} / \mathrm{m} \ell$ in $50 \%$ methanol containing $5 \mathrm{mM}$ ammonium formate infused at a flow rate of $10 \mu \mathrm{l} / \mathrm{min}$ produced a signal of appropriate abundance in ESI negative ion mode for the deprotonated precursor ion $[\mathrm{M}-\mathrm{H}]^{-}$using the turbo ion spray. Parameters, including nebulizer gas stream, curtain gas, and ion spray voltage, were optimized by flow injection analysis with a mobile phase flow rate of 0.3 $\mathrm{m} \ell / \mathrm{min}$. Tuning was performed using an automatic tuning tool included in the analyst software to determine the declustering and focusing potentials, fragmentation pattern, collision energy, and collision cell exit potential. Table 1 shows the optimum MS-MS conditions of the 15 NSAIDs. Deprotonated ions $[\mathrm{M}-\mathrm{H}]^{-}$(Q1 mass) were obtained for all NSAIDs, and were used as precursor ions in MS-MS experiments. The major fragment ions $\left[\mathrm{M}-\mathrm{H}-\mathrm{CO}_{2}\right]^{-}$were observed in most NSAIDs except some compounds. The product ions of loxoprofen, oxaprozin, phenylbutazone and acemetacin are considered to be $\mathrm{m} / \mathrm{z}=83$ (oxocyclopentyl part), $\mathrm{m} / \mathrm{z}=220\left[\mathrm{M}-\mathrm{H}-\mathrm{CH}_{2} \mathrm{CH}_{2} \mathrm{CO}_{2}\right]^{-}, \mathrm{m} / \mathrm{z}=279\left[\mathrm{M}-\mathrm{H}-\mathrm{CH}_{2} \mathrm{CH}_{2}\right]^{-}$ and $\mathrm{m} / \mathrm{z}=75 \quad\left(-\mathrm{OCH}_{2} \mathrm{COOH}\right)$, respectively. These fragment ions were sufficiently separated by Q3 in unit resolution, and these MRM transitions were selected for confirmation and quantification. These findings are in agreement with previous report ${ }^{23)}$. To determine the optimal composition, different mobile phases consisting of aqueous ammonium formate-acetonitrile were tested. The best signals were achieved using $5 \mathrm{mM}$ ammonium formate/acetonitrile $(60 / 40 \mathrm{v} / \mathrm{v})$. LC separation of the 15 NSAIDs was performed using an ODS-3 column. The development of the chromatographic system focused on short retention times and co-elution of these NSAIDs, paying attention to matrix effects as well as peak shapes. Thus, an increased flow rate of $0.3 \mathrm{~m} \ell / \mathrm{min}$ produced a good peak shape and made a runtime of $10 \mathrm{~min}$ possible (Fig. 3). 
Table 1 Optimum conditions for MS-MS (ESI negative ion mode) analysis of non-steroidal anti-inflammatory drugs

\begin{tabular}{lccccccc}
\hline & & \multicolumn{2}{c}{$\mathrm{m} / \mathrm{z}$} & $\mathrm{DP}$ & $\mathrm{EP}$ & $\mathrm{CE}$ & $\begin{array}{c}\text { CXP } \\
\text { Compound }\end{array}$ \\
\cline { 3 - 5 } & MW & Q1 Mass & Q3 Mass & (V) & (V) & (V) & (V) \\
\hline Acetaminophen & 151.2 & 150.1 & 107.2 & 70 & 10 & 26 & 7 \\
Loxoprofen & 246.3 & 244.9 & 83.3 & 65 & 10 & 24 & 5 \\
Naproxen & 230.3 & 229.1 & 184.8 & 55 & 10 & 10 & 11 \\
Ketoprofen & 254.3 & 253.1 & 208.9 & 65 & 10 & 12 & 13 \\
Fenoprofen & 241.4 & 241.0 & 197.1 & 60 & 10 & 12 & 15 \\
Flurbiprofen & 244.3 & 242.9 & 198.6 & 50 & 10 & 12 & 13 \\
Oxaprozin & 293.3 & 292.1 & 219.8 & 105 & 10 & 30 & 19 \\
Diclofenac & 296.1 & 295.0 & 251.9 & 65 & 10 & 18 & 15 \\
Phenylbutazone & 308.4 & 307.1 & 279.1 & 80 & 10 & 32 & 9 \\
Indometacin & 357.8 & 356.9 & 312.9 & 75 & 10 & 14 & 9 \\
Ibuprofen & 206.3 & 205.1 & 160.9 & 55 & 10 & 12 & 9 \\
Acemetacin & 415.8 & 415.1 & 74.9 & 85 & 10 & 44 & 5 \\
Mefenamic acid & 241.3 & 240.0 & 195.9 & 70 & 10 & 26 & 17 \\
Flufenamic acid & 281.2 & 280.0 & 235.6 & 75 & 10 & 28 & 15 \\
Tolfenamic acid & 261.7 & 261.0 & 216.6 & 45 & 10 & 24 & 19 \\
\hline
\end{tabular}

DP: declustering potential, EP: entrance potential, $\mathrm{CE}$ : collision energy, CXP: collision cell exit potential.
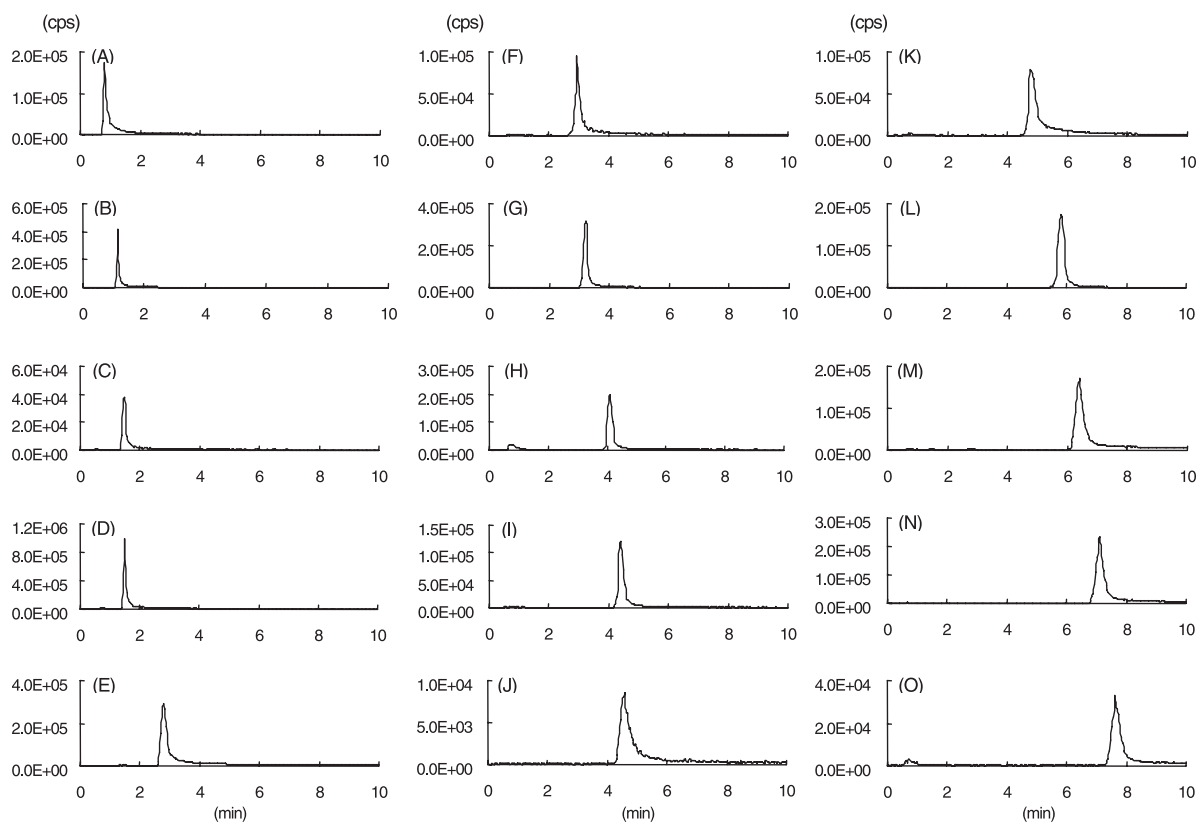

Fig. 3 MRM chromatograms obtained from $10 \mathrm{ng} / \mathrm{m} \ell$ of each standard compound by in-tube SPME/LC-MSMS in negative ionization mode.

Peaks: $\mathrm{A}=$ acetaminophen, $\mathrm{B}=$ loxoprofen, $\mathrm{C}=$ naproxen, $\mathrm{D}=$ ketoprofen, $\mathrm{E}=$ fenoprofen, $\mathrm{F}=$ flurbiprofen, $\mathrm{G}=$ oxaprozin, $\mathrm{H}=$ diclofenac sodium, $\mathrm{I}=$ indometacin, $\mathrm{J}=$ phenylbutazone, $\mathrm{K}=$ ibuprofen, $\mathrm{L}=$ acemetacin, $\mathrm{M}=$ mefenamic acid, $\mathrm{N}=$ flufenamic acid, $\mathrm{O}=$ tolfenamic acid. See Experimental section for LC/MS/MS conditions. 
Optimization of in-tube solid-phase microextraction and desorption

To optimize extraction of the 15 NSAIDs by intube SPME, several parameters, such as the stationary phase of the in-tube SPME capillary column and number and volume of draw/eject cycles, were investigated. In-tube SPME conditions were optimized with standard solution (10 ng/m $\ell$ of each) using an MS-MS detector (ESI negative). Four different capillary columns (DB-1, DB-17, Supelcowax, Carboxen-1006 PLOT) were evaluated for extraction efficiency. As shown in Fig. 4, the porous polymer-type capillary column (Carboxen-1006 PLOT) showed better extraction efficiency than the other liquid-phase type capillary columns (DB-1, DB17, and Supelcowax). As the Carboxen-1006 PLOT column has a large adsorption surface area, the amount extracted was greater than those obtained with the other liquid-phase type columns. To monitor the extraction time profiles of NSAIDs by in-tube SPME, the number of draw/eject cycles was varied from 0 to 25 using a Carboxen-1006 PLOT capillary. Extraction equilibrium of NSAIDs by in-tube SPME was obtained with 20 draw/eject cycles at a rate of $150 \mu \ell / m i n$. The effects of $\mathrm{pH}$ of the sample matrix on the extraction of NSAIDs by in-tube SPME were examined using several buffer solutions. Tris- $\mathrm{HCl}$ buffer $(\mathrm{pH}$ 8) was the most effective for extraction of these compounds, and the optimal buffer concentration was $20 \mathrm{mM}$.

The absolute amounts of NSAIDs extracted into the SPME capillary column were calculated by comparing peak area counts with the corresponding direct injection of the sample solution onto the LC column. At sample concentrations of $10 \mathrm{ng} / \mathrm{m} \ell, 0.6 \mathrm{ng}(5.8 \%)$ of acetaminophen, $0.6 \mathrm{ng}(6.5 \%)$ of loxoprofen, $1.3 \mathrm{ng}$
(13.2\%) of naproxen, 3. $0 \mathrm{ng}(29.9 \%)$ of ketoprofen, $1.2 \mathrm{ng}(12.1 \%)$ of fenoprofen, $1.7 \mathrm{ng}(16.9 \%)$ of flurbiprofen, $1.2 \mathrm{ng}(11.6 \%)$ of oxaprozin, $2.0 \mathrm{ng}$ (19.6\%) of diclofenac, $0.9 \mathrm{ng}(9.5 \%)$ of indometacin, $0.1 \mathrm{ng}$ (1.5\%) of phenylbutazone, $2.6 \mathrm{ng}(26.1 \%)$ of ibuprofen, $0.2 \mathrm{ng}(1.6 \%)$ of acemetacin, $0.5 \mathrm{ng}(4.9 \%)$ of mefenamic acid, $0.3 \mathrm{ng}(3.5 \%)$ of flufenamic acid, and $0.5 \mathrm{ng}(5.4 \%)$ of tolfenamic acid were extracted onto the Carboxen-1006 PLOT column by in-tube SPME. Although the extraction yields of these compounds were low, their reproducibility was good (relative standard deviations $\mathrm{RSD}<10 \%$ ) due to the use of an autosampler.

The mobile phase was found to be suitable for desorption of NSAIDs extracted into the stationary phase of the capillary column. Dynamic desorption of these compounds from the capillary was readily achieved by switching the six-port valve. The desorbed NSAIDs were transported to the LC column by mobile phase flow. No carryover was observed because the capillary column was washed and conditioned by draw/eject cycles of methanol and mobile-phase prior to extraction. The extraction and desorption of NSAIDs by the intube SPME method were accomplished automatically within $30 \mathrm{~min}$, and automated analysis of about 48 samples per day was also possible by overnight operation.

\section{Linearity, reproducibility and detection limit}

To test the linearity of the calibration curve, various concentrations of the 15 NSAIDs ranging from 0.1 to $10 \mathrm{ng} / \mathrm{m} \ell$ were analyzed by absolute calibration method. As shown in Table 2, a linear relationship was obtained for each compound in this range (six-point calibration), and the correlation coefficients ranged from 0.9997 to 1.0000 . The RSDs in each point ranged

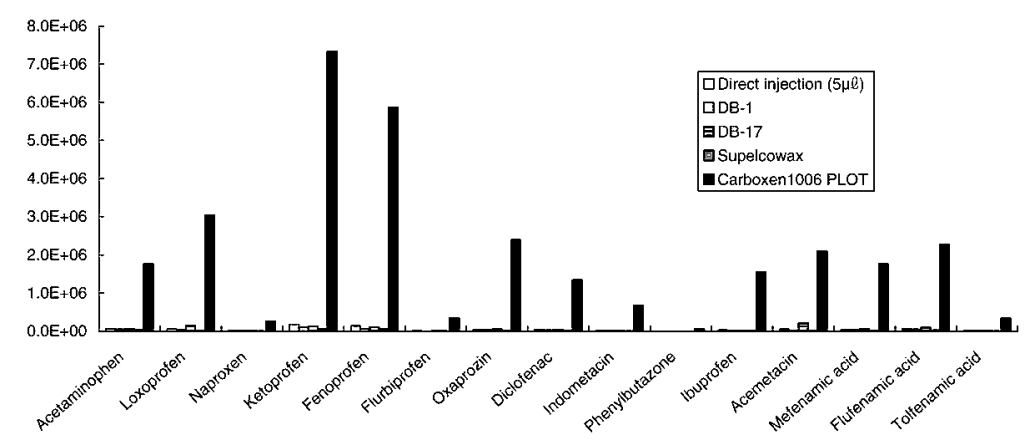

Fig. 4 Effects of capillary coatings on in-tube SPME of 15 NSAIDs. Each compound was extracted by 20 draw/eject cycles of $40 \mu \ell$ of the respective standard solution (each $10 \mathrm{ng} / \mathrm{m} \ell$ ) at a flow rate of 150 $\mu \ell / \min$. 
from 0.3 to $8.4 \%$. Instrumental precision was assessed by reduplicate injection $(n=5)$ of standard solutions on the same day and on different days. As shown in Table 2, within-day and between-day RSDs for quantitative analysis of $10 \mathrm{ng} / \mathrm{m} \ell$ standard solutions were in the range of $1.5 \sim 8.4 \%$ and $3.6 \sim 10.5 \%$, respectively. On the other hand, detection limits of the 15 NSAIDs ranged from 5 to $67 \mathrm{pg} / \mathrm{m} \ell$ with a signal-tonoise ratio of 3 . The in-tube SPME method showed 3 58 times higher sensitivity than the direct injection method (5 $\mu$ e injection), because these compounds in the sample solution were concentrated in the capillary column during draw/eject cycles. The developed method has almost same sensitivity with previous GCMS and LC-MS-MS methods [21-23], and can be applied to the quantitative analysis of environmental levels of these compounds.

\section{Application to the analysis of environmental wa- ters}

The method was applied to several environmental water samples. To confirm the validity of this method, known amounts of the 15 NSAIDs were spiked into river water, and their recoveries were calculated. As shown in Table 3 , the overall recoveries of these compounds were $81.9 \sim 100.4 \%$, and the relative standard deviations were $0.3 \sim 8.3 \%$. Fig. 5 shows MRM chromatograms obtained from wastewater, tap water, and river water. Loxoprofen was detected selectively at 458 $\pm 59 \mathrm{pg} / \mathrm{m} \ell$ in hospital wastewater. However, none of the other NSAIDs were detected in any of the samples tested in the present study. Ibuprofen, naproxen, ketoprofen, and diclofenac have been detected in various environmental water samples from around the world at concentration from $\mathrm{pg} / \mathrm{m} \ell$ to $\mathrm{ng} / \mathrm{m} \ell$ level ${ }^{7,13,15-17)}$. Although co-eluting matrix components may cause suppression of the analyte signal during electrospray ionization, no severe suppression was noticed for any of the compounds in the chromatogram of water samples used in this study. These results indicate that the proposed method remove interference compounds from the sample matrix by in-tube SPME and can measure trace levels of NSAIDs in real environmental samples. Superior point of the developed method in comparison with the previous methods ${ }^{21-23)}$ is automated operation from sample extraction to data analysis, and it can analyze 15 NSAIDs in environmental water samples without any other pre-treatment. Therefore, the method represents a useful tool for monitoring and determination of NSAIDs in environmental waters.

\section{ACKNOWLEDGEMENTS}

This work was supported by grants from the Shimadzu Science Foundation, the Yakumo Foundation for Environmental Science, Japanese Society for Food Sci-

Table 2 Linearity, reproducibility and detection limits of non-steroidal anti-inflammatory drugs by in-tube SPME/LC-MS-MS

\begin{tabular}{|c|c|c|c|c|c|c|}
\hline \multirow{2}{*}{ Compound } & \multirow{2}{*}{$\begin{array}{c}\text { Linearity }^{\text {a) }} \\
\begin{array}{c}\text { Correlation } \\
\text { coefficient }^{\text {b) }}\end{array}\end{array}$} & \multicolumn{2}{|c|}{ Reproducibility } & \multicolumn{2}{|c|}{ Detection limit $^{\mathrm{d})}(\mathrm{ng} / \mathrm{m} \ell)$} & \multirow{2}{*}{$\begin{array}{l}\text { In-tube SPME } \\
\text { /direct injection }\end{array}$} \\
\hline & & $\begin{array}{l}\text { Within-day RSD } \\
(\%)^{c)}\end{array}$ & $\begin{array}{c}\text { Between-day RSD } \\
(\%)^{\mathrm{c})}\end{array}$ & $\begin{array}{l}\text { Direct injection } \\
\qquad(5 \mu \ell)\end{array}$ & $\begin{array}{l}\text { In-tube } \\
\text { SPME }\end{array}$ & \\
\hline Acetaminophen & 1.0000 & 3.7 & 4.8 & 0.58 & 0.050 & 12 \\
\hline Loxoprofen & 1.0000 & 4.2 & 6.1 & 0.13 & 0.010 & 13 \\
\hline Naproxen & 1.0000 & 4.2 & 3.6 & 1.70 & 0.065 & 26 \\
\hline Ketoprofen & 1.0000 & 1.9 & 6.3 & 0.29 & 0.005 & 58 \\
\hline Fenoprofen & 0.9999 & 4.0 & 4.4 & 0.17 & 0.007 & 24 \\
\hline Flurbiprofen & 1.0000 & 1.5 & 4.6 & 2.00 & 0.059 & 34 \\
\hline Oxaprozin & 0.9997 & 3.0 & 4.7 & 0.13 & 0.005 & 26 \\
\hline Diclofenac & 1.0000 & 2.7 & 5.4 & 0.85 & 0.022 & 39 \\
\hline Phenylbutazone & 0.9997 & 8.4 & 7.6 & 0.17 & 0.059 & 3 \\
\hline Indometacin & 1.0000 & 2.8 & 7.1 & 1.12 & 0.058 & 19 \\
\hline Ibuprofen & 1.0000 & 2.2 & 5.3 & 0.33 & 0.006 & 55 \\
\hline Acemetacin & 1.0000 & 3.4 & 9.9 & 0.17 & 0.052 & 3 \\
\hline Mefenamic acid & 1.0000 & 4.7 & 9.2 & 0.24 & 0.024 & 10 \\
\hline Flufenamic acid & 1.0000 & 3.9 & 7.2 & 0.17 & 0.024 & 7 \\
\hline Tolfenamic acid & 1.0000 & 3.4 & 10.5 & 0.72 & 0.067 & 11 \\
\hline
\end{tabular}


Table 3 Recoveries of non-steroidal anti-inflammatory drugs spiked into river water

\begin{tabular}{lcccc}
\hline & & Recovery $(\%)$ & Spiked & Recovery $(\%)$ \\
\cline { 3 - 5 } Compound & $\begin{array}{c}\text { Spiked } \\
(\mathrm{ng} / \mathrm{m} \ell)\end{array}$ & Average $\pm \mathrm{SD}^{\mathrm{a})}$ & $(\mathrm{ng} / \mathrm{m} \ell)$ & Average $\pm \mathrm{SD}^{\mathrm{a})}$ \\
\hline Acetaminophen & 0.5 & $96.2 \pm 2.6$ & 10 & $100.4 \pm 2.4$ \\
Loxoprofen & 0.5 & $87.9 \pm 4.0$ & 10 & $87.1 \pm 1.0$ \\
Naproxen & 0.5 & $85.5 \pm 0.7$ & 10 & $97.4 \pm 1.0$ \\
Ketoprofen & 0.5 & $96.2 \pm 0.9$ & 10 & $86.3 \pm 0.3$ \\
Fenoprofen & 0.5 & $92.3 \pm 6.0$ & 10 & $87.2 \pm 0.5$ \\
Flurbiprofen & 0.5 & $98.0 \pm 2.3$ & 10 & $88.0 \pm 3.1$ \\
Oxaprozin & 0.5 & $81.9 \pm 6.8$ & 10 & $93.1 \pm 1.2$ \\
Diclofenac & 0.5 & $94.1 \pm 4.6$ & 10 & $89.9 \pm 4.2$ \\
Indometacin & 0.5 & $80.4 \pm 5.9$ & 10 & $89.5 \pm 3.4$ \\
Phenylbutazone & 0.5 & $95.0 \pm 2.3$ & 10 & $88.6 \pm 2.4$ \\
Ibuprofen & 0.5 & $95.7 \pm 3.2$ & 10 & $98.0 \pm 4.7$ \\
Acemetacin & 0.5 & $84.1 \pm 4.9$ & 10 & $86.9 \pm 1.2$ \\
Mefenamic acid & 0.5 & $93.1 \pm 2.8$ & 10 & $95.3 \pm 0.4$ \\
Flufenamic acid & 0.5 & $94.9 \pm 3.5$ & 10 & $93.4 \pm 1.1$ \\
Tolfenamic acid & 0.5 & $96.0 \pm 3.3$ & 10 & $97.9 \pm 3.0$ \\
\hline
\end{tabular}

a) Standard deviation $(n=3)$.

ence and Technology, and Japan Food Industrial Center, and Grants-in-Aid for Basic Scientific Research (B (2), No. 14370279; C, No. 19590049) and for Exploratory Research (No. 16659014).

\section{REFERENCES}

1) Jones, O.A.H., Voulvoulis, N. and Lester, J.N.: Human pharmaceuticals in the aquatic environment a review. Environ. Technol., 22 1383-1394 (2001).

2) Kummerer, K.: Drugs in the environment: emission of drugs, diagnostic aids and disinfectants into wastewater by hospitals in relation to other sources--a review. Chemosphere, 45 957-969 (2001).

3) Heberer, T.: Occurrence, fate, and removal of pharmaceutical residues in the aquatic environment: a review of recent research data. Toxicol. Lett., 131 5-17 (2002).

4) D.-Cruz, M.S., De Alda, M.J.L. and Barcelo, D.: Environmental behavior and analysis of veterinary and human drugs in solls, sediments and sludge. Trends Anal. Chem., 22 340-351 (2003).

5) Jones, O.A.H., Voulvouli, N. and Lester, J.N.: Potential ecological and human health risks associated with the presence of pharmaceutically active com- pounds in the aquatic environment. Crit Rev Toxicol., 34 335-350 (2004).

6) Jux, U., Baginski, R.M., Arnold, H.G., Kronke, M. and Seng, P.N.: Detection of pharmaceutical contaminations of river, pond, and tap water from $\mathrm{Co}_{0}$ logne (Germany) and surroundings. Int. J. Hyg. Environ. Health., 205 393-398 (2002).

7) Tixier, C., Singer, H.P., Oellers, S. and Muller, S.R.: Occurrence and fate of carbamazepine, clofibric acid, diclofenac, ibuprofen, ketoprofen, and naproxen in surface waters. Environ. Sci. Technol., 37 1061-1068 (2003).

8) Wiegel, S., Aulinger, A., Brockmeyer, R., Harms, H., Loffler, J., Reincke, H., Schmidt, R., Stachel, B., von Tumpling, W. and Wanke, A.: Pharmaceuticals in the river Elbe and its tributaries. Chemosphere, 57 107-126 (2004).

9) Boyd, G.R., Palmeri, J.M., Zhang, S. and Grimm, D.A.: Pharmaceuticals and personal care products (PPCPs) and endocrine disrupting chemicals (EDCs) in stormwater canals and Bayou St. John in New Orleans, Louisiana, USA. Sci. Total Environ., 333 137-148 (2004).

10) Tauxe-Wuersch, A., De Alencastro, L.F., Grandjean, 
(cps)

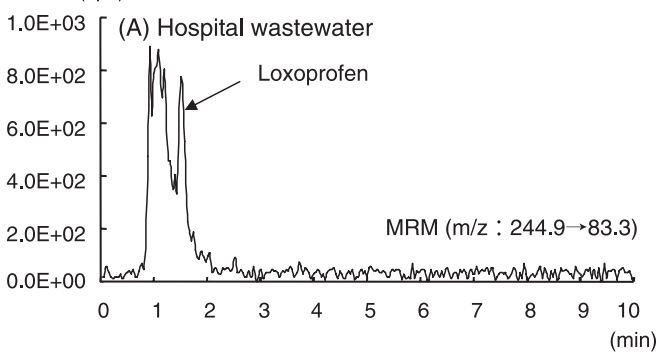

(cps)

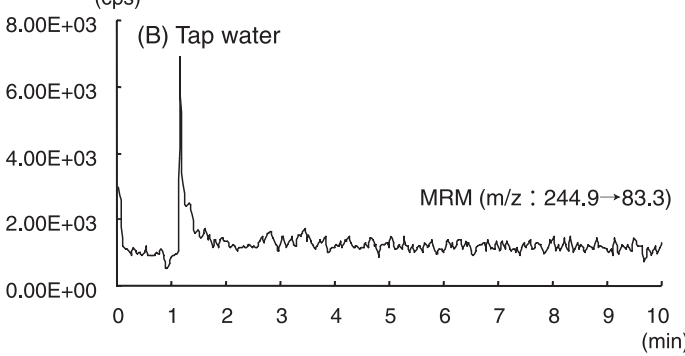

(cps)

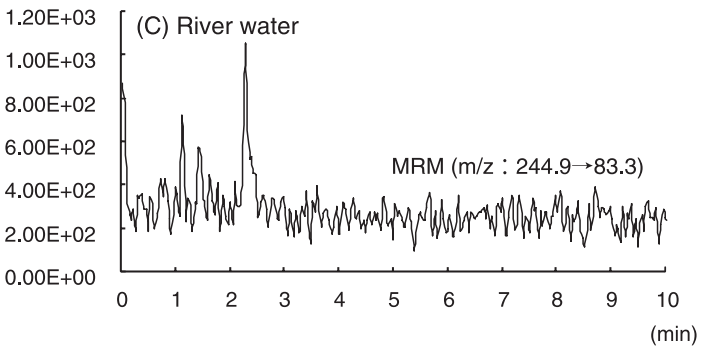

Fig. 5 MRM chromatograms of loxoprofen obtained from (A) hospital wastewater, (B) tap water, and (C) river water by in-tube SPME/LC-MS-MS. See Experimental section for in-tube SPME/LC-MS-MS conditions.

D. and Tarradellas, J.: Occurrence of several acidic drugs in sewage treatment plants in Switzerland and risk assessment. Water Res. 39 1761-1772 (2005).

11) Lindqvist, N., Tuhkanen, T. and Kronberg, L.: Occurrence of acidic pharmaceuticals in raw and treated sewages and in receiving waters. Water Res., 39 2219-2228 (2005).

12) Nakada, N., Tanishima, T., Shinohara, H., Kiri, K. and Takada, H.: Pharmaceutical chemicals and endocrine disrupters in municipal wastewater in Tokyo and their removal during activated sludge treatment. Water Res., 40 3297-3303 (2006).

13) Thomas, P.M. and Foster, G.D.: Determination of nonsteroidal anti-inflammatory drugs, caffeine, and triclosan in wastewater by gas chromatographymass spectrometry. J. Environ. Sci. Health A Tox. Hazard Subst. Environ. Eng., 39 1969-1978 (2004).

14) Antonić, J. and Heath, E.: Determination of NSAIDs in river sediment samples. Anal. Bioanal. Chem., 387 1337-1342 (2007).

15) $\mathrm{Wu}, \mathrm{J}$. and Lee, H.K.: Orthogonal array designs for the optimization of liquid-liquid-liquid microextraction of nonsteroidal anti-inflammatory drugs combined with high-performance liquid chromatography-ultraviolet detection. J. Chromatogr. A, 1092 182-190 (2005).

16) Debska, J., Kot-Wasik, A. and Namiesnik, J.: Determination of nonsteroidal antiinflammatory drugs in water samples using liquid chromatography coupled with diode-array detector and mass spectrometry. J. Sep. Sci., 28 2419-2426 (2005).

17) Marchese, S., Gentili, A., Perret, D., Ascenzo, G.D. and Pastori, F.: Quadrupole time-of-flight versus triple-quadrupole mass spectrometry for the determination of non-steroidal antiinflammatory drugs in surface water by liquid chromatography/tandem mass spectrometry. Rapid Commun. Mass Spectrom., 17 879-886 (2003)

18) Quintana, J.B., Rodil, R. and Reemtsma, T.: Suitability of hollow fibre liquid-phase microextraction for the determination of acidic pharmaceuticals in wastewater by liquid chromatography-electrospray tandem mass spectrometry without matrix effects. J. Chromatogr. A, 1061 19-26 (2004).

19) Hao, C., Lissemore, L., Nguyen, B., Kleywegt, S., Yang, P. and Solomon, K.: Determination of pharmaceuticals in environmental waters by liquid chromatography/electrospray ionization/tandem mass spectrometry. Anal. Bioanal. Chem., 384 505-513 (2006).

20) Vieno, N.M., Tuhkanen, T. and Kronberg, L.: Analysis of neutral and basic pharmaceuticals in sewage treatment plants and in recipient rivers using solid phase extraction and liquid chromatography-tandem mass spectrometry detection. J. Chromatogr. A, 1134 101-111 (2006).

21) Petrović, M., Hernando, M.D., Díaz-Cruz, M.S. and Barceló, D.: Liquid chromatography-tandem mass spectrometry for the analysis of pharmaceutical residues in environmental samples: a review. $J$. Chromatogr. A., 1067 1-14 (2005). 
22) Gentili, A.: Determination of non-steroidal anti-inflammatory drugs in environmental samples by chromatographic and electrophoretic techniques. Anal. Bioanal. Chem., 387 1185-1202 (2007).

23) Farré, M., Petrovic, M. and Barceló, D.: Recently developed GC/MS and LC/MS methods for determining NSAIDs in water samples. Anal. Bioanal. Chem., 387 1203-1214 (2007).

24) Eisert, R. and Pawliszyn, J.: Automated in-tube solid-phase microextraction coupled to high-performance liquid chromatography. Anal. Chem., 69 3140-3147 (1997).

25) Mitani, K., Narimatsu, S., Izushi, F. and Kataoka, H.: Simple and rapid analysis of endocrine disruptors in liquid medicines and intravenous injection solutions by automated in-tube solid-phase microextraction/high performance liquid chromatography. J. Pharm. Biomed. Anal., 32 469-478 (2003).

26) Kataoka, H., Narimatsu, S., Lord, H.L. and Pawliszyn, J.: Automated in-tube solid-phase microextraction coupled with liquid chromatography/ electrospray ionization mass spectrometry for the determination of $\beta$-blockers and metabolites in urine and serum samples. Anal. Chem., 71 42374244 (1999).

27) Kataoka, H., Lord, H.L. and Pawliszyn, J.: Simple and rapid determination of amphetamine, methamphetamine, and their methylenedioxy derivatives in urine by automated in-tube solid-phase microextraction coupled with liquid chromatography-electrospray ionization mass spectrometry. J. Anal. Toxicol., 24 257-265 (2000).

28) Mitani, K., Fujioka and M., Kataoka, H.: Fully automated analysis of estrogens in environmental waters by in-tube solid-phase microextraction coupled with liquid chromatography-tandem mass spectrometry. J. Chromatogr. A, 1081 218-224 (2005).

29) Mitani, K. and Kataoka, H.: Determination of fluoroquinolones in environmental waters by intube solid-phase microextraction coupled with liquid chromatography-tandem mass spectrometry. Anal. Chim. Acta, 562 16-22 (2006).

30) Kataoka, H.: Automated sample preparation using in-tube solid-phase microextraction and its application - a review. Anal. Bioanal. Chem., 373 31-45 (2002). 